\title{
A Capstone Engineering Modeling Course for Developing Creative Problem- Solving
}

\section{Dr. Megan Reissman, University of Dayton}

Dr. Reissman studied mechanical engineering at Cornell University (BS) and Northwestern University $(\mathrm{PhD})$. She currently teaches engineering design, analysis, and experimentation courses in the mechanical engineering department of University of Dayton. She specializes in biomechanics and robotic systems.

\section{Dr. Allison L. Kinney, University of Dayton}

Allison L. Kinney is an Assistant Professor in the Mechanical and Aerospace Engineering Department at the University of Dayton. She received her BS in Biomedical Engineering from Tulane University in 2005 and her MS and PhD in Mechanical Engineering from The University of Texas at Austin in 2007 and 2010, respectively. Her interests include biomechanics of human movement, musculoskeletal modeling and simulation, and engineering education.

\section{Dr. Kevin Patrick Hallinan, University of Dayton}

Dr. Hallinan is a Professor and former Chair of the Mechanical and Aerospace Engineering at the University of Dayton. As Chair in 2008, he established a Master's Program in Renewable in Clean Energy, which now has 55 students from 20 nations. His research interests, which have led to over 105 peer-reviewed papers and over $\$ 4 \mathrm{M}$ in research funding, have been diverse, beginning with satellite thermal management, leading to conduct of an experiment aboard a Space Shuttle, to now a focus on building energy informatics. He is the founding Director of the newly formed Energy Informatics Center at UD. He also is co-founder of a start-up company, Dropoly (dropoly.com/play) and serves in the community as Co-Chair for the Executive Advisory Committee to Dayton Regional Green. Hallinan has been received numerous awards for teaching (UD Alumni Award in Teaching, 1998, Student Government Association Outstanding Faculty Award, 2008, Pi Tau Sigma, 2002\&2011, Epsilon Delta Tau Engineering Fraternity, 1993, 2003, 2008, 2010, Phi Sigma Rho, 2011) and service (Marianist Service Award, 2004, and Montgomery County Exemplary Service Award, 2013). 


\title{
A Capstone Engineering Modeling Course for Developing Creative Problem-Solving
}

\author{
A.L. Kinney ${ }^{1}$, M.E. Reissman ${ }^{1}$, K.P. Hallinan ${ }^{1}$ \\ ${ }^{1}$ University of Dayton, Dayton, OH, U.S.A.
}

\begin{abstract}
Over the past twenty years, nearly all job growth in the United States has emerged from new companies and organizations with assumedly innovative products, services, and practices. Yet, the nurturing of student creative thinking through truly open-ended problem solving is infrequent in engineering education. Engineering design projects most often come with constraints and requirements that often negate opportunities for creative growth. In response, over the past six years at the University of Dayton, a capstone engineering modeling course has been developed and evolved. Initially this course focused on asking students to develop computational solutions to well-specified modeling problems ideally building upon on previously taken fundamental mechanical engineering courses. However, it was clear very early that students' abilities to develop models for the projects assigned to which computational tools could be applied was noticeably weak. Thus the course emphasis shifted to highly open-ended modeling efforts. What has emerged over time is a course based upon projects involving two person student teams driven by very general needs and which integrate foundational mechanical engineering subject areas. The projects are designed to only provide the general problem space for unique student innovations. With their concepts developed, they then proceed to 'create' their engineering model. This process of defining the problem, breaking down their problem to manageable parts, envisioning assumptions to make their models tractable, and then applying foundational engineering processes and knowledge all provide immense challenge to students. In all stages of the innovation and modeling process, the students are expected demonstrate progress, before given individualized suggestions for improvement from their instructors. Recent assessment has documented the following results. Upon completion of the course students acknowledge improvement in creativity, problem identification, an ability to breakdown real problems, and an ability to model. They also acknowledge improved confidence in their foundational knowledgeable and heightened excitement about a career which enables them to work creatively as engineers.
\end{abstract}

\section{Introduction: Our Experience in Teaching Engineering Modeling}

In 2011 one of the authors of this study was assigned the teaching of MEE 460 - Engineering Analysis at the University of Dayton. At that time, this senior level course was mostly an applied computational methods course. Students were given well defined problems across all disciplines in mechanical engineering requiring advanced computational solutions. The faculty role in this course was primarily facilitative; helping students learn new computational approaches such as optimization, Monte Carlo simulation, neural network solutions, and finite element solutions. Often the solutions were highly code intensive. Ultimately, with facilitation, most students succeeded. 
Over time, this faculty integrated more open projects into the course; projects still requiring computational solutions, but with prior development of analytical models premised on learning in earlier mechanical engineering courses. In the early instantiations of this approach, the faculty made an important observation. Most students were ill-prepared and unable to develop the models needed. The faculty facilitation required was much greater than that required for completing the computational solutions to the models they were developing. Only a small number of students demonstrated strong ability to succeed in the modeling process on their own. Interestingly, these weren't necessarily students with high GPA. In fact, in the first semester that more open-ended projects were introduced, the best student in the class was a young man with just a 2.6 GPA, well below the average in his class.

A common characteristic describing the most successful students began to emerge. They were all students who would describe themselves as creative. These students seemed to have a strong excitement for the nature of the problems assigned, a stronger intuitive understanding of mechanical engineering fundamentals irrespective of GPA, and an ability to abstract models to describe the real systems they were analyzing. When asked "What aspects of their education helped to nurture their creative problem-solving skill?", in truth, they had difficulty identifying anything. In the end, it was our belief that nurturing students to be creative problem solvers, capable of creating new ideas and validating their creations with models based upon engineering fundamentals was to be the goal of our course. In addition, a larger goal was that this approach would also be integrated into the courses preceding our capstone modeling course. This realization has prompted us to better understand what creativity is and the role that creativity plays in real-world engineering analysis processes.

The following describes: why nurturing these abilities is essential for the world today; what nurturing creativity requires; and how engineering education is in general not succeeding in nurturing this growth. It also points to the well-defined area of Problem-Based Learning as a guide for how creativity might be more strongly infused engineering curriculum.

\section{Background: Infusing Creativity into Engineering Problem Solving}

In 2001, Richard Florida, author of the book Rise of the Creative Class, attributed nearly all job growth in the United States period prior to the writing of his book, to the creatives; namely engineers, scientists, artists, entrepreneurs, and the like. [1]. Recent studies have re-echoed this finding. For example, the Kauffman Foundation found that over the period from 1988 and 2012, nearly all job growth was attributable to new and young companies. Companies five years or older had eliminated more jobs than they created in all but eight of those years. The job creating firms were recognized for the economic dynamism they injected through increased market competition and spurring innovation [2].

So what is meant by creativity? Relative to engineering, Kazerounian and Foley define it in terms of the ability to generate new ideas or new associations between existing ideas. Requisite to such developments is a willingness to take chances; an ability to make unique connections between ideas; flexibility and imagination; a willingness to question normal approaches; and inquisitiveness and intuitiveness [3].

So, how are universities doing in nurturing growth in creativity? A 2015 survey of employers sponsored by the American Association of Colleges says "not very good." The survey findings showed that potential employers believed that only one-quarter of graduates from all disciplines were both creative and had acceptable critical thinking and problems solving skills. They also showed that only $18 \%$ of employers 
felt that students were prepared to work with people from different backgrounds, despite the fact that $96 \%$ of employers felt that students should have to solve problems with peers whose views are different than theirs [4].

Kazerounian and Foley's 2007 study of how engineering programs' address creativity development echo this observation. They found that few, if any engineering programs, specifically seek to: foster inquisitiveness or open-mindedness; help students become comfortable with ambiguity; provide continuous practice of ideation; encourage students to search for multiple answers; and allow students to take risks, fail, or have ownership of the education they wish to receive, among others [3].

But, maybe creativity skill development should be considered. The National Academy of Engineering in its 2004 report The Engineer of 2020: Visions of Engineering in the New Century, while acknowledging the growing scope of the challenges to humanity ahead and the complexity and diversity of the technologies of the 21 st century, emphasizes that creativity as a quality of engineers will be increasingly important [5]. Further the vital role of creativity in problem-solving, for identifying objectives and constraints, as well as imagining the critical potentially conflicting perspectives which could influence the solutions developed has long been established. Creativity also next weighs in on the development of possible solutions and assessment of the viability of these through argument construction and articulation of personal beliefs and assumption [6].

Given the role of 'innovation' projects in developing creativity, while aiding learning (including the process of self-directed learning), the field of Project Based Learning (PBL) offers insight into what defines excellent projects. PBL promotes student-centered learning and emphasizes the role of authentic tasks, e.g., tasks which address real-world problems, require application of prior knowledge, require research to gain new knowledge needed to address the problem, and result in a solution that can have impact in the world. Ideally projects have heterogeneous teams in order to broaden perspective and the scope of solutions emerging [7].

The value of PBL in student learning has been documented by an increasing number of researchers. For example, Geier et al. demonstrated better subject knowledge understanding through standard testing for students who had learned through a PBL approach [8]. Boaler that PBL led to superior student ability to answer applied and conceptual problems [9]. While some suggest that there remains a debate on the value of project-based learning [10], Michael Prince's seminal study of active learning approaches seems to demonstrate that debate should be put to rest. His comprehensive review of literature documenting the value of active, collaborative, cooperative, problem-based, and project-based learning is certain, ..., if done right [11]. It is not surprising that the U.S. common core curriculum for K-12 now preferences inquiry, problem, and project-based learning approaches.

\section{Capstone Engineering Creative Problem Solving Course}

As a part of their capstone experience, senior mechanical engineering students at the University of Dayton complete a semester long course (MEE 460 - Engineering Analysis) which emphasizes the application of physics-based and data mining models toward three open ended project prompts. More importantly, this course emphasizes and encourages the use of creative thinking in determining and developing the models 
needed to analyze the systems in their overall project. In the Fall 2016 semester, 93 total students were engaged in three projects common to all of the sections. A summary of each project and the primary disciplinary domains is detailed in Table 1 . For each of these projects students were encouraged to invent systems that had market potential; while also having the potential to support more environmentally sustainable solutions.

Table 1. Projects addressed by students in MEE 460 - Engineering Analysis in the Fall 2016 semester

\begin{tabular}{|l|l|l|}
\hline Project Title & Project Summary & Primary Disciplinary Domains \\
\hline Vertical Farming & $\begin{array}{l}\text { Develop a vertical farming system to } \\
\text { increase food productivity and minimize } \\
\text { water consumption where needed } \\
\text { worldwide. }\end{array}$ & Structures, Fluid Mechanics, Economics \\
\hline Human-thermal Comfort & $\begin{array}{l}\text { Develop a human thermal comfort } \\
\text { system. }\end{array}$ & $\begin{array}{l}\text { Heat Transfer, Biomechanics, } \\
\text { Electronics (some), Economics }\end{array}$ \\
\hline Data Mining & $\begin{array}{l}\text { Apply statistical-based data analytics } \\
\text { approach(es) to multivariate dataset of } \\
\text { choice. }\end{array}$ & Statistical-Based Modeling \\
\hline
\end{tabular}

In order to render truly creative-problem solving experiences, the nature of these projects was set to be highly open. The projects were thus framed to provide the students only a space to work within; a space that would inevitably force reliance upon knowledge within specific sub-domains (never one) in mechanical engineering. Within this space, students would define their own real situation and problem. They would create their own problem. Additionally, not only were students to develop 'physics-based' models; they would now be tasked with developing other types of models such as cost models and databased statistical models in order to help students understand that modeling was something that they would do in all stages of their future engineering career.

The projects engaged students in a modeling process involving the steps shown Table 2 below. Given a broadly defined space to work in, in step 1 , students ideated the specific problem they wanted to address and solve. They also were specified all that they know about the problem. In step 2, they fully defined the goals from their modeling efforts. Throughout the course of all of the projects, students were reminded again and again to think back to these goals, and encouraged to revise the goals as they learned more. In step 3 (Decide what should be modeled and why), students imagined the model(s) they would create to match their physical system. This process didn't simply ask students to rely upon knowledge they already theoretically had. Rather, it forced them to research in order to learn how they might model the system they were analyzing. This research might take them back to foundational knowledge they had already been exposed to or to new knowledge; although at the beginning the modeling efforts tended to mainly emphasize the former. The point is that there had to be early imagining of the ultimate model(s) that would be developed in order to inform the assumptions needed to simplify their system to make it modelable (step 5). 
The model development process itself was also subdivided into two linked process steps. In developing their models, students were asked to consider how they might subdivide their system in order to develop tractable and simple models they could grasp and solve (steps 6 and 7). The validation and interpretation steps in the original cycle were expanded as well. In step 9, students were asked to question the results they obtained; specifically, to evaluate whether the results they obtained made sense. They were then asked to estimate how the assumptions they'd made to develop their model(s) had affected their solution and thus their ability to achieve the stated objectives for the models they developed.

In light of knowledge that modeling is an iterative process, a final step was added (step 11), which asked students to consider what they could have done to improve their models, based upon the results they had obtained, which they may have considered unrealistic, or based upon relaxation of some of the assumptions they had made. They were also asked to consider adjustment of their objectives based upon results they had obtained.

Table 2. Engineering modeling process employed

\begin{tabular}{|c|l|}
\hline Step & \multicolumn{1}{|c|}{ Description } \\
\hline 1 & $\begin{array}{l}\text { Specify problem to address and all known parameters and aspects of the } \\
\text { problem. }\end{array}$ \\
\hline 2 & Fully define goals that modeling will achieve. \\
\hline 3 & Decide what should be modeled and why. \\
\hline 4 & Identify and characterize relevant parameters. \\
\hline 5 & Make assumptions to simplify. \\
\hline 6 & Define systems/subsystems/forces/flows. \\
\hline 7 & Develop models to achieve goals. \\
\hline 8 & Solve models. \\
\hline 9 & Question results. Evaluate effects of assumptions on solutions. \\
\hline 10 & Discuss how results contribute to achievement of project goals. \\
\hline 11 & Suggest improvements to model. \\
\hline
\end{tabular}

Table 3 below offers a summary of the diversity of student innovations from the first two projects described in Table 1. The creative space for the first project was a vertical farming system. Within this space, students had the freedom to consider any system they wished that utilized vertical space (or tiers) and was consistent with the goal of increased growing productivity with less fresh water. The scale of the projects emerging ranged from a system mounted to a door in an apartment, to an indoor/outdoor system that would meet $100 \%$ of the vegetable needs of a Midwest American family, to a mass scale vertical rice farm, and an orange tree farm in California. The diversity displayed in the systems was also reflected in the target markets, which ranged from apartment dwellers, to suburban residents, to mass production agricultural, and developing world markets. The diversity in selections of scale and location for the systems also lent to diversity in the models needed. For systems designed for water limited environments, students had to determine the minimum water requirements for the plants (including factors such as transpiration losses). Large scale systems had significant structural issues. The means by which water was supplied to the plants (through soil, water mists, or drip systems to roots) required different hydraulic analysis. 
The creative space defined for the second project was even 'bigger.' The only requirement was for a human thermal comfort system. The freedom given for this project was attractive to the students. Four in ten of the students preferred this project as a result. Again, there was a diversity of ideas and models. One team envisioned sports sunglasses with rechargeable ammonium nitrate capsules offering a large amount of cooling with a small mass. Another team, interested in a career with NASA, envisioned a solar thermal heating system for a moveable human cabin on Mars. Another group, both marathon runners, envisioned heated running gloves that would keep hands warm in very cold environments with minimal weight. Another team, having interest in developing products for people with disabilities, posed a cooling vest for people with cerebral palsy or multiple-sclerosis using thermoelectric Peltier cooling. Their research showed that maintenance of body temperature in such people helps mitigate spasticity issues exacerbated by exercise and hot outdoor conditions. As with the first projects, the models developed by the students were driven by their inventions. The project employing ammonium nitrate required modeling of the endothermic chemical reaction. The systems relying upon thermoelectric devices inevitably required heat transfer modeling, as well as modeling of the thermoelectric energy conversion process. The Mars moveable human cabin heated via a solar thermal system required modeling of the solar to heating conversion, as well as heat transfer from the transport lines and the cabin itself. A common theme emerged in many of the student project selections. When students were given freedom to base their systems in areas that matched their interests, creativity was engaged and demonstrated across the majority of students, rather than just the small subset of students naturally inclined towards creative thinking. When this happens, there is certainly more enthusiasm and ownership of the work they are doing. As one student noted in his reflection of the class "I really appreciated getting the opportunity to define what I worked on, for the first time in my college experience."

Another aspect of the creative problem-solving effort is notable. In order to develop models, students had to both identify and learn what they needed to know. In the first project for example, no students had any experience with plant growth, transpiration, mist generation, soil water flows, etc... yet they were able to successfully develop the models they needed. In the second project, almost no students had ever considered metabolic functioning of the body. None had experience with thermoelectric devices, evaporative cooling, etc...., and yet they were able to successfully develop such models as needed to achieve their goals.

Table 3. Summary of projects students were engaged in application of the creative problem-solving model

\begin{tabular}{|l|l|}
\hline Project & Sample Inventive Ideas / Models Developed \\
\hline $\begin{array}{l}\text { Develop a vertical } \\
\text { farming system to } \\
\text { increase food } \\
\text { productivity and } \\
\text { minimize water } \\
\text { consumption where } \\
\text { needed worldwide. }\end{array}$ & $\begin{array}{l}\text { Inventive Idea: Mass produced three layer corn production vertical farm with drip irrigation } \\
\text { Models Developed: } \\
\text { (i).Transpiration model for water loss from plants } \\
\text { (ii). Structural model of vertical farm } \\
\text { (iii). Hydraulic model of flow through drip irrigation orifices }\end{array}$ \\
\cline { 2 - 2 } & $\begin{array}{l}\text { Inventive Idea: Apartment door mounted additive manufactured vertical garden mailed soil/seed } \\
\text { packets } \\
\text { Models Developed: } \\
\text { (i).Model to define optimal crops } \\
\text { (ii). Cost model } \\
\text { (iii). LED lighting model } \\
\text { (iv). Hydraulic model of flow gravity fed water system }\end{array}$ \\
\hline
\end{tabular}




\begin{tabular}{|c|c|}
\hline & $\begin{array}{l}\text { Inventive Idea: Aeroponic vertical rice farm with solar powered LED lighting for India } \\
\text { Models Developed: } \\
\text { (i).Transpiration model for water loss from plants } \\
\text { (ii). Structural model of vertical farm } \\
\text { (iii). Hydraulic model of misting flow system }\end{array}$ \\
\hline & $\begin{array}{l}\text { Inventive Idea: Indoor/outdoor vertical garden for } 100 \% \text { of family produce needs (customizable) } \\
\text { Models Developed: } \\
\text { (i).Transpiration model for water loss from plants } \\
\text { (ii). Growth model of plants } \\
\text { (ii). Structural model of vertical farm } \\
\text { (iii). Hydraulic model of flow through pipes and soil }\end{array}$ \\
\hline & $\begin{array}{l}\text { Inventive Idea: Vertical orange tree farm for California } \\
\text { Models Developed: } \\
\text { (i).Transpiration model for water loss from plants } \\
\text { (ii). Growth model of plants } \\
\text { (ii). Structural model of vertical farm } \\
\text { (iii). Hydraulic model of flow through pipes and soil }\end{array}$ \\
\hline \multirow[t]{5}{*}{$\begin{array}{l}\text { Develop a human } \\
\text { thermal comfort } \\
\text { system. }\end{array}$} & $\begin{array}{l}\text { Inventive Idea: Thermoelectric cooled vest for adult/young adult with cerebral palsy or multiple- } \\
\text { sclerosis to reduce spasticity brought on from being overheated } \\
\text { Models Developed: } \\
\text { (i). Heat transfer from torso to ambient w/ and w/out vest } \\
\text { (ii). Metabolic model of human with diagnosed diseases } \\
\text { (iii). Thermoelectric Peltier device energy conversion }\end{array}$ \\
\hline & $\begin{array}{l}\text { Inventive Idea: Sports glasses with heat absorbing ammonium nitrate reversible reaction } \\
\text { Models Developed: } \\
\text { (i).Heat transfer model from head w/ and w/out glasses } \\
\text { (ii). Human thermal comfort perception model } \\
\text { (iii). Exothermic chemical reaction to evaluate cooling potential }\end{array}$ \\
\hline & $\begin{array}{l}\text { Inventive Idea: Heated running gloves linked to smart fitness watch } \\
\text { Models Developed: } \\
\text { (i).Heat transfer model from hand to environment w/and w/out heated glove } \\
\text { (ii). Metabolic model of local heating in hand } \\
\text { (iii). Hydraulic model of flow through drip irrigation orifices }\end{array}$ \\
\hline & $\begin{array}{l}\text { Inventive Idea: Thermoelectric heated and cooled thermal comfort office chair to reduce central } \\
\text { heating/cooling requirements } \\
\text { Models Developed: } \\
\text { (i).Heat transfer model from body to chair and to ambient } \\
\text { (ii). Metabolic model of body } \\
\text { (iii). Thermoelectric cooling and heating model } \\
\text { (iv). Zonal heating/cooling model }\end{array}$ \\
\hline & $\begin{array}{l}\text { Inventive Idea: Moveable cabin with solar thermal heater for Mars } \\
\text { Models Developed: } \\
\text { (i). Solar thermal energy conversion for Mars environment } \\
\text { (ii). Hydraulic model for fluid transport } \\
\text { (iii). Heat transfer model for fluid transport lines and cabin }\end{array}$ \\
\hline
\end{tabular}

For the last project, focusing on the development of statistical modeling of engineering problems, the students were given complete autonomy in selecting their problem and problem goals. They were 
challenged to find a publically available dataset featuring multiple factors, ideally connected to their interests. For this project, students were first introduced to statistical based data modeling approaches (linear, non-linear, neural networks, and regression trees) and to R, an open-source statistical software. As a backup, building energy data meeting the data requirements for the project was made available to students. About a third of the students opted to use the data provided them.

This project, above all, helped students recognize that modeling doesn't simply relate to physical systems, but can potentially be connected to everything that they do as an engineer. It also helped them particularly see the opportunity of employing data analytics for engineering modeling. It also certainly gave the creative students an opportunity to fully define and implement their problem.

\section{Assessment to Validate Growth and Learning}

Consistently, the faculty leading this course would ask "What is the value of this course?" Did students grow from the experience? Did student understanding of mechanical engineering grow? Was student creativity expanded or just exploited? Did the learning of the modeling process have a long term impact on the students? There had not yet been an attempt to quantify student development during the course and we did not know if these target outcomes were being achieved. We honestly didn't know the answers to these questions. Yet there was belief in the process and belief that we could make the process better. Thus, we sought to assess the course beyond simple anecdotal experience to determine the answers to such questions. In addition to identifying the potential impact of the course on student development, we sought to identify factors that correlated with student development and overall course success.

An assessment vehicle was addressed to measure student preferences toward the projects, student attitudes toward the structure of the course, student preferences to the skills and abilities most relevant to modeling, student perceptions of the place for modeling and creativity in their career, and student perception of their knowledge in specific mechanical engineering topics. The assessment was administered through a survey both prior to the semester (termed pre-assessment) and at the end of the semester (termed post-assessment). A total of 89 students completed the pre-assessment and 93 students completed the post-assessment. However, there were only 84 students completing both assessments. The summative survey results are based upon this sample size, which still represents over $90 \%$ of the students enrolled in the three sections of the course.

Table 4 summarizes the wording of the overall survey structure for each of the four main categories. Table 5 summarizes the assessment questions organized by assessment category and the mean pre- and delta post-assessment scores on the 5 point scale with 1 being associated with strongly disagree/low confidence and 5 associated with strongly agree/high confidence. Delta post-assessment is the difference in the rating for the post-assessment relative to the pre-assessment.

Table 4. Pre- and post-assessment wording of survey scales and section prompts

\begin{tabular}{|l|l|l|}
\hline $\begin{array}{l}\text { Numeric } \\
\text { Value }\end{array}$ & $\begin{array}{l}\text { Perceptions of Course Structure, } \\
\text { Skills, and Career }\end{array}$ & Perceptions of Disciplinary Knowledge \\
\hline
\end{tabular}




\begin{tabular}{|l|l|l|}
\hline & $\begin{array}{l}\text { Please rate your agreement with each } \\
\text { statement on the following scale. }\end{array}$ & $\begin{array}{l}\text { Please rate the level of confidence you feel in } \\
\text { completing an analysis for each area on the } \\
\text { following scale. }\end{array}$ \\
\hline 1 & Strongly disagree & Low confidence \\
\hline 2 & Disagree & Somewhat low confidence \\
\hline 3 & Moderate & Moderate confidence \\
\hline 4 & Agree & Somewhat high confidence \\
\hline 5 & Strongly agree & High confidence \\
\hline
\end{tabular}

Table 5. Pre- and post-assessment of student perceptions of the course structure, their skill development, their attitudes relative to their career, and their knowledge of mechanical engineering topics $(n=84)$

\section{Question}

Perceptions of Course Structure

This class gave me great flexibility in how I approached problems

This class was too constrained in how the problems were presented

This class gave me many opportunities to define problems

In this class, I would have prefered if there was one specific path to the answer

This class has nurtured my creativity

In this class, I preferred working in a group to solve problems

Perceptions of Skills

I am a creative problem solver

I can break down a problem into manageable parts

I can research on my own to gain information for problem solving

I can make assumptions to simplify a model

I can critically evaluate the work of others

I can critically evaluate my own work

I can quantify/describe differences between a real system and a model

\section{Impact on Perceptions of Career}

I feel excited when approaching open ended problems

I feel uncomfortable when approaching open ended problems

I expect to work creatively to develop new products, processes, and/or services

I expect to work in multidisciplinary teams

I expect to model and analyze engineering systems

Perceptions of Disciplinary Knowledge

\section{Post $\Delta($ Post-Pre $)$}

2.28

4.21

2.62

4.17

4.27

4.00

1.16

$4.13 \quad 1.28$

$4.30 \quad 1.21$

$4.08 \quad 1.21$

$3.97 \quad 1.10$

$4.03 \quad 1.21$

$4.02 \quad 1.27$

3.93

1.23

2.66

$-1.27$

$4.34 \quad 1.14$

$4.42 \quad 1.16$

$4.20 \quad 1.16$ 
Mechanical structures

Fluid flow

Heat transfer

Mechanical dynamics

Electric circuits

Statistical data analysis

Material strength/failure

Numerical optimization

A number of conclusions can be drawn from Table 5. Relative to student perspectives of the course, the students clearly understood the emphasis of the course on open-ended problem-solving and creativity. Further, they acknowledged that the course had been successful in nurturing their creativity. Most shocking is the student perceptions of their improvement in numerous skills based upon the observed difference of their perception over the course of just one semester. The difference between the pre- and post- assessment of every single skill saw at least a 1.1/5 increase, with the lowest improvement associated with improvement in the ability to critically evaluate others (1.1) and the highest associated with the abilities of breaking down problems into manageable parts (1.28) and describing the differences between real and modeled systems (1.27). Skill improvement in creative problem-solving, self critique of work, making assumptions to simplify a model, and in conducting research required to gain information needed for problem-solving experienced strong self-perceived growth.

Relative to the impact of the course on their perception of the roles of creative problem-solving and modeling in their career, the same magnitude of improvement in perception was observed as with skills. Students now strongly believed (4.2 versus 3.04 ) that they would develop engineering models throughout their career and expected to have to work creatively on new products, processes, and/or services (4.34 versus 3.2 a priori). Finally, there was notable increase in the expectation of working in multi-disciplinary teams (4.42 ver 3.26 a priori). While the course did not enable students to work with students from other disciplines, the instructors often emphasized that overall system design typically impacted the analysis of more than one model, and hence in industry, engineers with different specializations would be expected to work collaboratively in this process.

Finally, while not necessarily a goal of the course (this was observed through the course of the semester anecdotally from student comments), student perception of their knowledge of specific mechanical engineering topics increased substantially. Relative to mechanical structures, fluid flow, heat transfer, mechanical dynamics, electrical circuits, mechanical dynamics, statistical data analysis, mechanical strength/failure, and numerical optimization, student confidence in their knowledge of these topics increased minimally by $1.19 / 5.0$. Ironically, the only topics truly addressed during the projects were mechanical structures/failure, fluid flow, heat transfer, and statistical data analysis. It is likely that the students understood that the confidence they had gained in breaking down real systems and developing models transcended topic. The practice of having to learn on their own within one area could be applied to any other.

The following seeks to extract additional information from the survey results, particularly seeking to establish demographic trends from the results. Figure 4 shows the project preferences for the students. 
The Human Thermal Comfort project was noted to be the favorite, with the vertical farming project as the second most common preference. The data mining project was the least favorite; however, $20 \%$ of the students said that it was their preferred project, and it was the next favorite for a majority of students. A shared characteristic between the Human Comfort and Data Mining project was an extensive allowance for personalization and creativity. A difference between these two projects was that the Data Mining project required learning new skills and techniques in the area of computational methods and with the specific software R. Student's baseline comfort with, and natural level of inclination towards, applied computational methods likely contributed towards their preference on this project. Conversely, Human Comfort did not require students to learn new analysis methods or software.

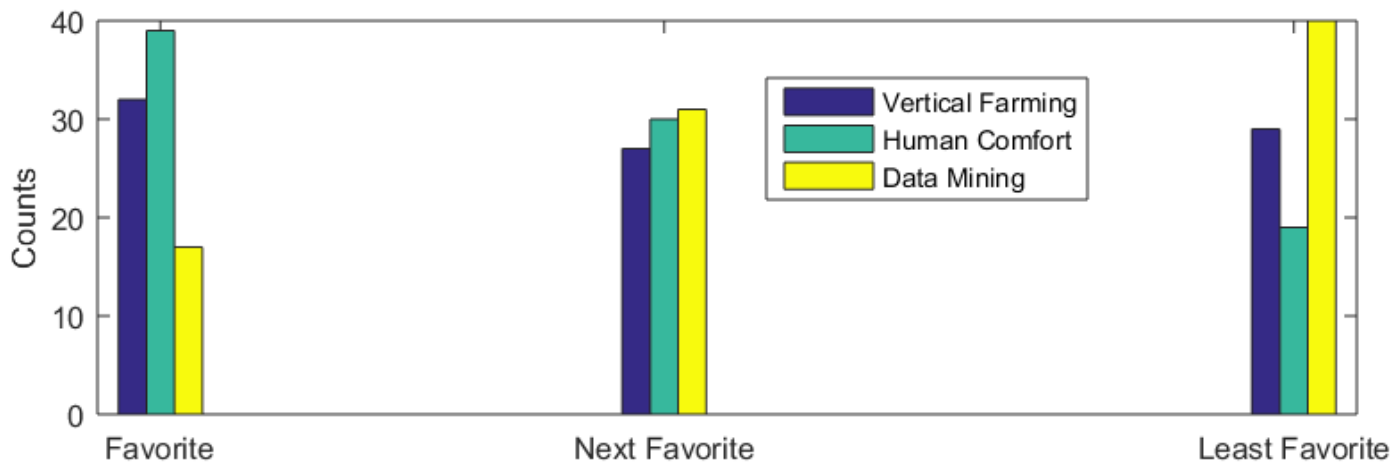

Figure 4. Student project preferences

Table 6 seeks to show the correlation between student demographic data and project preference.

Demographic data included faculty perception of student creativity (0 or 1), GPA, gender, and amount of co-op experience. There was generally weak correlation for all. The strongest correlation existed between GPA and the Data Mining project (-0.23), with higher GPA students not valuing this project as much as others. Interestingly this result may have been due to the fact that the lower GPA students don't see themselves developing physical-based models in their careers, but now see the opportunity for data based modeling. The next strongest correlation was between students with co-op experience preferring the Human-thermal Comfort project more strongly (0.19). This result is likely because of the entrepreneurial nature of this project, with students effectively being asked to create a new product. Students with co-op experience may see increased value in projects with this attribute because of the experiences they have gained from industry.

Table 6. Correlation between student demographic data and project preference

\begin{tabular}{|l|r|r|r|}
\hline & \multicolumn{3}{|c|}{ Projects } \\
\hline Correlation Variable & Vertical Farming & Human Thermal Comfort & Data Mining \\
& 0.09 & 0.07 & -0.16 \\
\hline $\begin{array}{l}\text { Faculty Perception of } \\
\text { Creativity }\end{array}$ & 0.17 & 0.05 & -0.23 \\
\hline GPA & -0.14 & 0.07 & 0.09 \\
\hline Gender & -0.03 & 0.19 & -0.15 \\
\hline Amt. of Co-op & & & \\
\hline
\end{tabular}


Experience

$+2$

The importance of the same correlation variables in terms of specific assessments related to creative growth, career expectations, and knowledge was also evaluated (Table 7). Relative to student perception of growth in creativity, there was a small but significant positive correlation to faculty perception of student creativity and GPA; meaning that the higher GPA students and students with more highly refined creative skills felt more strongly that the course had nurtured their creativity. Relative to the shift in student expectation of creative functioning in their career, the strongest correlation was to GPA. Perhaps the confidence that higher performing students gained from the course enabled them to believe more strongly that they would be capable of working creatively throughout their career. Relative to the shift in student perception of their expectation of modeling in their career, the greatest correlation once again was relative to faculty perception of student creativity and GPA. Again, growth in confidence of their ability to both work creatively and imagine and develop models has helped them see opportunities for such functioning in their careers. Last of all, as evidenced by the Heat Transfer category, which really mirrored all other mechanical engineering topic categories, the strongest correlation of the shift in students perception of their knowledge was for the high GPA students and the students identified by faculty as having strong creative ability. In summary, the course seems to have greater impact on the higher performing students. However, it cannot be stated strongly enough: the perceptions of nearly every student shifted positively in nearly every category.

Table 7. Correlation between student demographic data and student skills, career expectation, and mechanical engineering knowledge

\begin{tabular}{|l|r|r|r|r|}
\hline & \multicolumn{4}{|c|}{ Skill, Career Expectations, and Knowledge Assessment Questions } \\
\hline $\begin{array}{l}\text { Correlation } \\
\text { Variable }\end{array}$ & $\begin{array}{c}\text { This class nurtured } \\
\text { my creativity }\end{array}$ & $\begin{array}{c}\text { Expectation of } \\
\text { working creatively } \\
\text { in career }\end{array}$ & $\begin{array}{c}\text { Expectation of } \\
\text { modeling in career }\end{array}$ & $\begin{array}{c}\text { Self-Perception of } \\
\text { Knowledge of Heat } \\
\text { Transfer }\end{array}$ \\
\hline $\begin{array}{l}\text { Faculty Perception } \\
\text { of Creativity }\end{array}$ & 0.1309 & 0.04 & 0.13 & 0.25 \\
\hline GPA & 0.14 & 0.15 & 0.21 & 0.19 \\
\hline Gender & -0.06 & 0.04 & 0.05 & -0.17 \\
\hline $\begin{array}{l}\text { Amt. of Co-op } \\
\text { Experience }\end{array}$ & -0.05 & -0.03 & -0.07 & 0.07 \\
\hline
\end{tabular}

\section{Conclusions}

This study describes what is believed to be a very unique capstone engineering modeling course, designed to provide students with open-ended creative problem definition and solving experience. In these experiences, students both apply previous knowledge and learn new knowledge required to develop their models.

The results have demonstrated significant improvement in student perception of their creativity, problemsolving skills, and disciplinary knowledge in mechanical engineering. The results also seem to suggest 
that the higher performing students, in terms of both GPA and faculty perception of student creativity, have experienced the greatest improvements. Lastly, the results strongly suggest a linkage between disciplinary learning and the process of addressing real problems requiring system break-down and imagining and applying assumptions in order to develop models that are solvable.

Further study lies ahead. While the results have shown a linkage between creativity and the ability to develop models, this linkage was based solely upon the faculty's perception of students' creative abilities. More rigorous instruments for assessing creativity will be utilized in the future.

Should this linkage be conclusively established, it will be essential to imagine and implement a curriculum that brings open-ended, creative problem-solving to the entirety of the curriculum. Arguably, a curriculum which believes that because content has been covered, students know it, isn't sufficient. The theory they learn is meaningless unless they are able to apply it to new problems and develop new models to support their designs. The inclusion of, if not sole reliance, on problems that challenge students to creatively develop models of real systems in fundamental engineering courses seems a logical next step.

\section{References}

[1] R. Florida, The Rise of the Creative Class, New York, New York: Basic Books, 2001.

[2] K. Foundation., "The Importance of Young Firms for Economic Growth," Entrepreneurship Policy Digest, 14 Sept. 2015.

[3] K. Kazerounian and S. Foley, "Barriers to creativity in engineering education: A study of instructors and students perceptions," Journal of Mechanical Design, vol. 129, pp. 761-768, 2007. [4] S. Jaschik, "Well Prepared in Their Eyes," Inside Higher Education, 21 Jan. 2015.

[5] National Academy of Engineering, The Engineer of 2020: Visions of Engineering in the New Century, Washington D.C.: National Academies Press, 2004.

[6] G. Pahl, W. Beitz, J. Feldhusen and Grote, K. H. Engineering Design: A Systematic Approach (The 3rd edition). London: Springer, 2007.

[7] G. F. Smith, "Problem-based learning: can it improve managerial thinking?" Journal of Management Education, Vol. 29, pp.357-376, 2005. http://dx.doi.org/10.1177/1052562904269642

[8] Geier, R., P. C. Blumenfeld, R.W.Marx, J. S. Krajcik, E. Soloway, and J. Clay-Chambers, 2008, Standardized test outcomes for students engaged in inquiry-based curricula in the context of urban reform, Journal of Research in Science Teaching, 45(8), pp. 922-39.

[9] Graham, R., "UK Approaches to Engineering Project-Based Learning," White Paper sponsored by the Bernard M. Gordon-MIT Engineering Leadership Program, 2010.

[10] Boaler, J. (2002). Learning from teaching: Exploring the relationship between reform curriculum and equity. Journal for Research in Mathematics Education, 33(4), 239-258.

[11] Prince, M. (2004), Does Active Learning Work? A Review of the Research. Journal of Engineering Education, 93: 223-231. doi:10.1002/j.2168-9830.2004.tb00809.x. 